\title{
Levodopa and dopamine dynamics in Parkinson's disease metabolomics
}

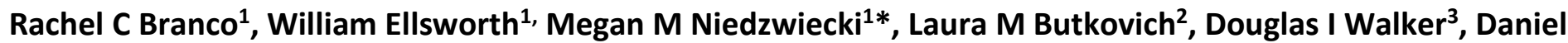 \\ E Huddleston ${ }^{4}$, Dean P Jones ${ }^{3}$, Gary W Miller ${ }^{5}$
}

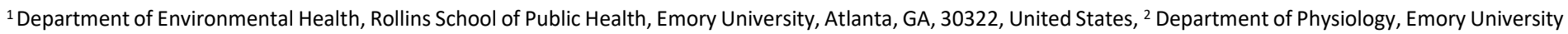

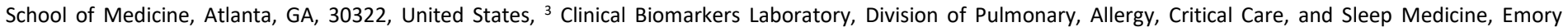

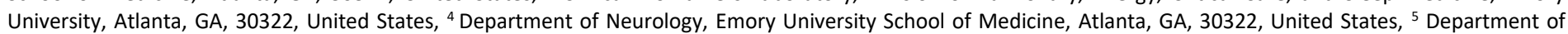

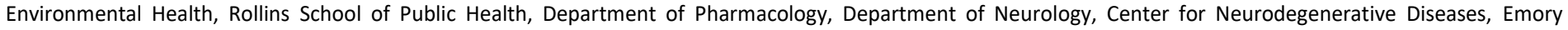

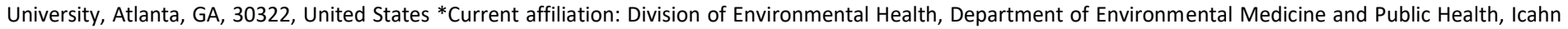
School of Medicine at Mount Sinai, New York, NY 10029

Parkinson's disease (PD) is a progressive neurological disorder caused by a combination of genetic and environmental factors. Metabolomics is a powerful tool that can be used to screen for potential biomarkers, exogenous toxicants, and metabolic network changes associated with disease states. Here, we used high-resolution metabolomics to compare over 10,000 plasma metabolic features from older adults with and without PD in an untargeted approach. We performed a network analysis that demonstrates that the presence of the PD drug levodopa influences variation observed between PD and control patients. Metabolome wide association studies and discrimination analysis identified significant differentiation in the metabolomics profile of older adults with and without PD. Notably, 15 metabolic features (ten of which we putatively identified) differed between PD and control adults with $p<0.05$ and a corrected false discovery rate less than $20 \%$. Furthermore, 13 metabolic networks were identified to be functionally different between PD and non-PD patients. Lastly, the dopaminergic toxic intermediate DOPAL differed between PD and nonPD populations, which supports the dopaminergic sequestration model of PD. These individual metabolites and metabolic networks have been implicated in past PD pathogenesis models, including the beta-carboline harmalol and the glycosphingolipid metabolism pathway including the ganglioside GM2. We recommend that future studies take into account the confounding effects of levodopa in metabolomic analyses of disease versus control patients, and encourage validation of several promising metabolic markers of PD.

Parkinson's disease | metabolomics | levodopa | dopamine

Parkinson's disease (PD) is a common progressive neurodegenerative disorder. Though PD pathology affects multiple systems, the most distinctive symptom of PD is motor dysfunction, including bradykinesia, rigidity, and postural instability [1]. PD is caused by the loss of nigrostriatal dopamine neurons [2], though other brain regions are affected in PD pathology $[3,4]$. At the time of PD diagnosis, approximately $60 \%$ of nigrostriatal dopamine neurons are already lost [5]. To counteract the loss of dopamine neurotransmission after dopamine cell loss, patients take an oral medication containing levodopa (L-dopa), a dopamine precursor which can cross the blood-brain barrier and helps overcome the paucity of endogenous dopamine in the brain [6]. In this way, L-dopa acts to slow the progression of motor symptoms [7]. However, there are no treatments to either halt or reverse PD progression. Despite the cluster of unwanted complications associated with treatment, Ldopa remains the mainstay pharmacotherapy for PD.

Because earlier identification of PD is critical to effective treatments, research has focused on the identification of biomarkers, protective factors, and/or relevant pathways that characterize PD risk and pathology. High-resolution metabolomics methods provides a powerful tool to characterize the molecular profile present in biological samples. Untargeted metabolomics can simultaneously characterize thousands of endogenous and exogenous compounds within a biological sample - collectively called the metabolome [8-11].
Due to the treatment considerations of sampling human patients, most metabolomics studies of human PD have sampled from PD patients that are actively taking L-dopa or that are Ldopa deprived for a only short period of time prior to sample collection [12-14]. The first aim of this study was to test how much L-dopa accounts for the metabolic differences between PD patients and controls. We found that the majority of metabolic profile differences between Parkinson's and control patients can be explained by the presence of L-dopa, even in metabolic networks theoretically independent from dopamine metabolism. In this way, this paper acts as a warning to future biomarker and metabolomics researchers to account for the effects of treatment when evaluating effects of pathology.

The second aim of this study was to evaluate biomarker metabolites or pathways that differ between PD and control patients. Despite the complicating effects of L-dopa, we identified metabolic differences that are likely due to PD pathology rather than the L-dopa treatment. Our findings are consistent with past experimental literature suggesting that the antioxidant betacarboline harmalol and the glycosphingolipid pathway are altered in PD and provides the first demonstration showing these metabolic variations are detectable in peripheral blood Furthermore, this metabolic analysis underscores the altered dopamine dynamics present in PD patients.

Author summary: Prognostic diagnosis of disease is key for identifying treatment options that slow disease progression and improve patient quality of life. This is particularly important in Parkinson's disease, where patients could greatly benefit from treatment before their latent sickness becomes problematic. Past studies have compared the blood of Parkinson's patients with the blood of healthy adults in an effort to find a biomarker for Parkinson's disease-however, in most of these past studies, the patients with Parkinson's disease were taking the Parkinson's medication levodopa. In our study, we analyzed the plasma metabolomics profiles of people with and without Parkinson's disease. We found that the presence or absence of levodopa was the main difference between the blood of people with and without Parkinson's disease. Furthermore, levodopa was associated with alterations in other metabolic pathways in a way that makes it hard to determine which differences are due to the disease and which are drug-related. Despite this complicating factor, we identified compounds and pathways that differ between Parkinson's and control patients, including harmalol and the glycosphingolipid pathway. With further testing, these markers may help doctors identify Parkinson's risk earlier in life.

The authors declare no conflict of interest. Correspondence should be addressed to racliburn@gmail.com or gary.miller1967@me.com. This work was supported by the Michael J. Fox Foundation (MJF 10854) to D.E.H.,National Institutes of Health (Grants R01ES023839, P30ES019776, F31NS084739, F31DA037652, F31NS089242, P50NS071669, and T32ES012870) and The Lewis AQ8 Dickey Memorial Fund to G.W.M. Special thanks to R. McMurray for sample collection 
bioRxiv preprint doi: https://doi.org/10.1101/306266; this version posted May 22, 2018. The copyright holder for this preprint (which was not certified by peer review) is the author/funder, who has granted bioRxiv a license to display the preprint in perpetuity. It is made available under aCC-BY-NC-ND 4.0 International license.

\begin{tabular}{|c|c|c|c|}
\hline Characteristic & $P D(n=21)$ & Control (n=13) & p-value \\
\hline $\begin{array}{l}\text { Sex } \\
\text { Male } \\
\text { Female }\end{array}$ & $\begin{array}{l}10(47.6 \%) \\
11(52.4 \%)\end{array}$ & $\begin{array}{l}5(38.5 \%) \\
8(61.5 \%)\end{array}$ & 0.73 \\
\hline Age (mean $\pm s d)$ & $61.7 \pm 8.0$ & $71.3 \pm 5.4$ & $0.001 * *$ \\
\hline $\begin{array}{l}\text { Race } \\
\text { Caucasian } \\
\text { African American }\end{array}$ & $\begin{array}{l}21(100 \%) \\
0(0 \%)\end{array}$ & $\begin{array}{l}10(76.9 \%) \\
3(23.1 \%)\end{array}$ & $0.048 *$ \\
\hline $\begin{array}{l}\text { Educational level } \\
\text { Years of education } \\
\text { Less than high school } \\
\text { High school } \\
\text { Some college } \\
\text { Associate/vocational } \\
\text { Bachelor's } \\
\text { Master's } \\
\text { Doctorate }\end{array}$ & $\begin{array}{l}15.7 \\
1(4.8 \%) \\
3(14.3 \%) \\
3(14.3 \%) \\
1(4.8 \%) \\
8(38.1 \%) \\
5(23.8 \%) \\
0(0 \%)\end{array}$ & $\begin{array}{l}17.8 \\
0(0 \%) \\
1(7.7 \%) \\
0(0 \%) \\
0(0 \%) \\
5(38.5 \%) \\
5(38.5 \%) \\
2(15.4 \%)\end{array}$ & $0.035 *$ \\
\hline $\begin{array}{l}\text { PD characteristics } \\
\text { UPDRS-III score } \\
\text { Disease duration } \\
\text { L-dopa equivalent } \\
\text { MOCA score } \\
\text { NMSQ score }\end{array}$ & $\begin{array}{l}10.9 \pm 6.5 \\
7.7 \pm 3.4 \\
\text { years } \\
817.8 \pm \\
372.8 \\
27.6 \pm 2.1 \\
3.7 \pm 2.5\end{array}$ & $\begin{array}{l}2.6 \pm 2.14 \\
\text { N/A } \\
\text { N/A } \\
26.6 \pm 3.7 \\
9.2 \pm 3.8\end{array}$ & $\begin{array}{l}0.0001 \\
* * * \\
0.35 \\
<0.0001 \\
* * *\end{array}$ \\
\hline
\end{tabular}

Table 1. Description of study participants. 21 PD patients and 13 aged controls were studied. Differences between groups were calculated by Fisher's exact test for Sex and Race, and t-test for all other categories.

\section{Results}

There were no differences in the proportions of men and women between the PD and control group, but differences were found in age, race, and educational level, with the PD group more likely to be Caucasian, younger, and less educated. As expected, PD and control groups also differed in motor and non-motor symptoms of PD (Table 1).

We performed t-tests to identify $\mathrm{m} / \mathrm{z}$ features differentially expressed in patients with PD based upon a false discovery rate (FDR) correction threshold of $20 \%$. Fifteen $\mathrm{m} / \mathrm{z}$ features were different between the two groups (Fig 1, Table 2). Predictably, the five top annotated compounds were either PD drugs or their metabolites, all of which were elevated in PD patients (Fig 2A). These PD drug metabolites met at least 2 criteria for identity, i.e.. accurate mass match to predicted adduct (Level 5 identitv [151), co-elution with authentic standard. ion dissociation spectrum matching that of known compound. or association with known pathwav or metabolic network (Supplementarv Table 1), are indicated by metabolite name. Other features are denoted bv associated accurate mass match to known metabolite (Level 5 identity) along with $m / z$ and retention time, as indicated. Additionally, the toxic dopamine metabolite 3,4dihydroxyphenylacetaldehyde (DOPAL) was elevated in PD patients (Fig 2B). Several compounds, including harmalol, were elevated in control patients relative to PD patients (Fig 2C). Five of the fifteen metabolic features provided no matches in chemical databases.

Each patient's L-dopa equivalent dose was highly correlated with the primary L-dopa metabolite $\left(\mathrm{m} / \mathrm{z} 212.092, \mathrm{r}^{2}=0.6559\right)$. Furthermore, L-dopa metabolite abundance and Unified Parkinson's Disease Rating Scale Part III (UPDRS) scores were highly correlated $\left(\mathrm{r}^{2}=0.4562\right)$, indicating that, as expected, patients with more severe PD symptoms tended to have more Ldopa in their blood.

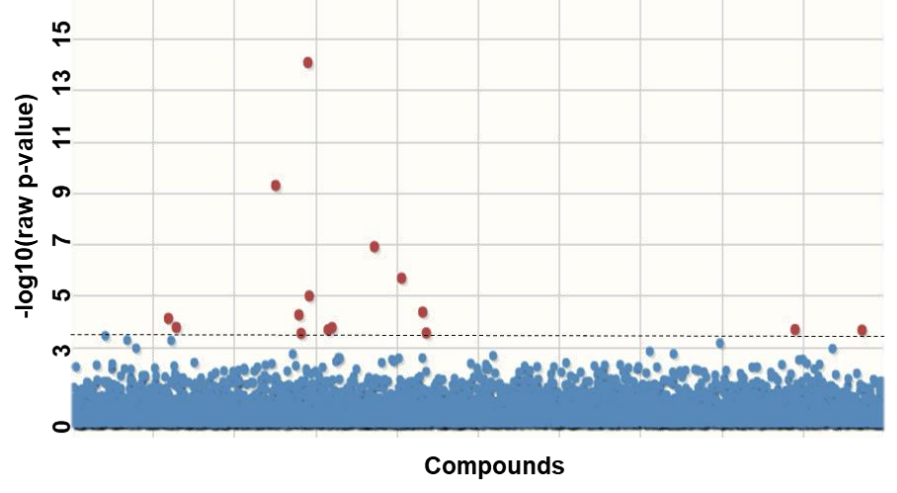

\begin{tabular}{|c|c|c|c|c|c|c|}
\hline$m / z$ & $\begin{array}{l}\text { RT } \\
\text { (s) }\end{array}$ & Putative identity & Function & $\begin{array}{l}\text { Higher } \\
\text { in }\end{array}$ & $\begin{array}{c}p- \\
\text { value }\end{array}$ & FDR \\
\hline 212.092 & 71 & 3-methoxytyrosine & $\begin{array}{c}\text { PD drug } \\
\text { metabolite }\end{array}$ & PD & $8.33 \mathrm{E}-15$ & 7.56E-11 \\
\hline 195.0653 & 71 & 3-methoxytyrosine & $\begin{array}{l}\text { PD drug } \\
\text { metabolite }\end{array}$ & PD & 5.17E-10 & $2.34 \mathrm{E}-06$ \\
\hline 256.0555 & 66 & 3-methoxytyrosine & $\begin{array}{l}\text { PD drug } \\
\text { metabolite }\end{array}$ & PD & $1.27 \mathrm{E}-07$ & 0.000383 \\
\hline 278.0327 & 142 & DOPA sulfate & $\begin{array}{l}\text { PD drug } \\
\text { metabolite }\end{array}$ & PD & 2.13E-06 & 0.004821 \\
\hline 213.0951 & 73 & 3-methoxytyrosine & $\begin{array}{l}\text { PD drug } \\
\text { metabolite }\end{array}$ & PD & $1.05 \mathrm{E}-05$ & 0.019062 \\
\hline 292.0489 & 143 & Unknown & Unknown & PD & 4.46E-05 & 0.067475 \\
\hline 207.1104 & 69 & Unknown & Unknown & Control & 5.74E-05 & 0.074343 \\
\hline 149.0599 & 74 & Unknown & Unknown & PD & 7.87E-05 & 0.089226 \\
\hline 153.0548 & 76 & DOPAL & $\begin{array}{c}\text { DA } \\
\text { metabolite }\end{array}$ & PD & 0.000177 & 0.15867 \\
\hline 225.0826 & 70 & Unknown & Unknown & Control & 0.000178 & 0.15867 \\
\hline 916.6712 & 55 & glycerophospolipids & $\begin{array}{l}\text { Lipid } \\
\text { membrane }\end{array}$ & PD & 0.000215 & 0.15867 \\
\hline 223.0846 & 69 & Harmalol & Antioxidant & Control & 0.000219 & 0.15867 \\
\hline 1427.752 & 132 & Ganglioside GM2 & $\begin{array}{l}\text { Lipid } \\
\text { membrane }\end{array}$ & Control & 0.000227 & 0.15867 \\
\hline 294.846 & 64 & gylcerophospholipids & $\begin{array}{l}\text { Lipid } \\
\text { membrane }\end{array}$ & Control & 0.000292 & 0.18283 \\
\hline 208.1141 & 69 & Unknown & Unknown & Control & 0.000302 & 0.18283 \\
\hline
\end{tabular}

Fig 1. Manhattan plot for the untargeted MWAS. The $x$ axis contains features arranged in order of $m / z$, and the y axis contains - $\log 10$ of the unadjusted $p$ value. Table 2. 15 compounds resulted from the untargeted MWAS comparing features in PD patients against control patients. Using the Human Metabolome Database (HMDB), likely candidates for 10 of the 15 metabolic features were identified; the remaining 5 were provided no matches.

We performed orthogonal partial least squares-discriminate analysis (OPLS-DA), which uses supervised learning to determine the principal components that most differentiate populations across multiple dimensions [16]. Using OPLS-DA, the metabolic profile of PD and control patients differentiated into two distinct groups (Fig 3). Within the OPLS-DA analysis, we identified features that most contributed to the model using the covariance and correlation between the features and the class designation. As expected, the features that were most influential in driving the OPLS-DA model corresponded to the features identified as most significantly different between PD and controls in the t-test analysis. To evaluate if OPLS-DA merely stratified 
A
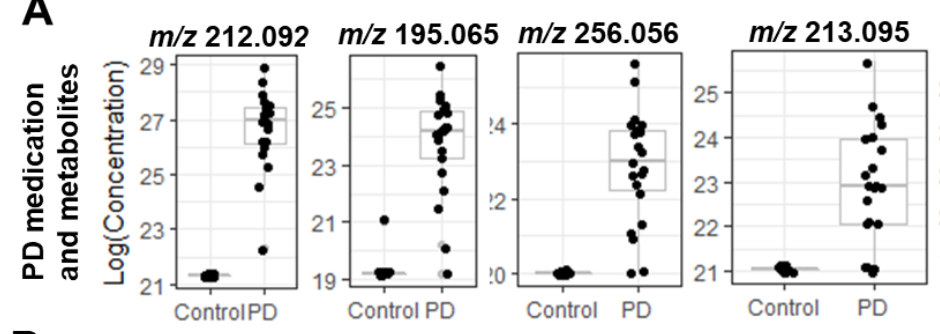

B

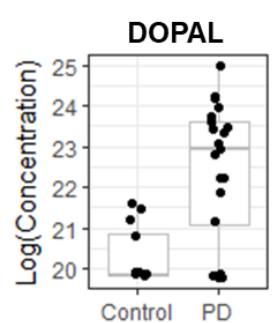

C

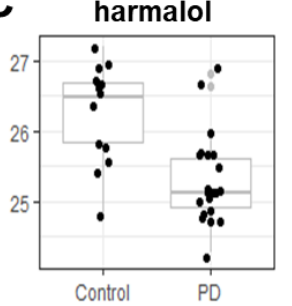

D

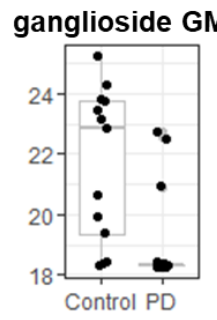

Fig 2. Boxplots for the 8 annotated compounds from the untargeted MWAS. The $x$ axis contains clinical status and the y axis contains Log10(Concentration).

patients according to presence of L-dopa, we completed a second OPLS-DA after manually eliminating signals corresponding to Ldopa or direct L-dopa metabolites. Even with these PD drug features removed, the two populations differentiated into two distinct groups (Supplementary Fig 1).

However, the removal of L-dopa and its direct metabolites from the OPLS-DA analysis does not guarantee that the downstream effects of L-dopa are eliminated. In order to test the correlation between L-dopa and other metabolites, we performed a separate analysis to predict which metabolites correlated with Ldopa (Supplementary Fig 2). We then performed pathway analysis to elucidate the metabolic pathways that were altered between PD and control patients (Supplementary Fig 3). By comparing the results of these metabolic pathway analyses, we identified several major metabolic pathways altered in PD patients and correlated with plasma L-dopa (Fig 4, Supplementary Table 2). Notably, every metabolic network that was different between PD and control plasma metabolites was also affected by the presence of L-dopa.

\section{Discussion}

\section{L-dopa confounds PD versus control comparisons.}

The top five differential features measured in PD and control patients' plasma were a PD drug and its metabolites (Table 2). The elevated levels of these L-dopa metabolites in PD patient plasma acted as a de facto positive control. The known oral dose of L-dopa strongly correlated with $\mathrm{m} / \mathrm{z}, 212.092$, which was identified as 3-methyltyrosine. Therefore, we deemed the $\mathrm{m} / \mathrm{z}$ 212.092 feature as an acceptable proxy for L-dopa concentration in patient plasma samples:

Feature reduction analysis using OPLS-DA showed that the metabolic profiles of PD versus control patients were distinctly different across two principal components (Fig 3). We also performed OPLS-DA on PD versus control patient plasma metabolites after manually removing the metabolic features corresponding to L-dopa or direct L-dopa metabolites. This approach also resulted in distinct clustering of PD and control populations across two principal components. However, this result does not prove that PD drugs did not drive the separation of the two groups, as the biological response to L-dopa could have driven the separation between PD and control groups despite the omission of L-dopa itself. Indeed, L-dopa is correlated with many metabolic networks, so it is likely that downstream effects of Ldopa alter critical metabolite features that define each metabolic profile and underlie the OPLS-DA identified differences between PD and control patients.

The comparison of metabolic pathways between PD and control patients revealed a number of biological pathways that were different in PD. However, in this analysis, it was impossible

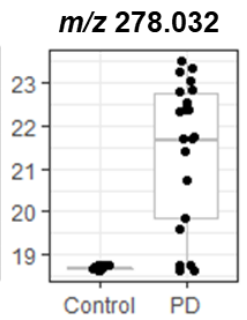

to tell whether metabolic pathways are altered due to PD pathology or by PD treatment. To this end, we performed a separate pathway analysis restricted to PD patients to identify which biological pathways were most strongly associated with L-dopa. All pathways that were identified using metabolites that were different between PD and control patients were also correlated with the presence of L-dopa. This includes networks that we would expect to be perturbed by L-dopa administration, such as tyrosine and biopterin metabolism. However, many of these pathways were correlated with Ldopa despite the lack of any a priori suspicion of biological interaction. In previous studies, these pathways were assumed to be altered in PD patients due to PD pathology, but the analysis shows that L-dopa is a confounding factor to that interpretation.

These results provide a warning to future metabolomics studies using prevalent disease cases the extent to which treatment of the disease confounds identification of underlying pathology. Since L-DOPA levels correlate well with many nondopamine metabolic pathways, simply removing L-DOPA from the dataset after the data collection is likely not sufficient to reduce confounding effects of the drug.

It is not surprising that the treatment of the condition (in this case, L-dopa for PD) has a close relationship with pathways that are pathological in the disease state (i.e. dopamine metabolism). Dopamine dynamics are undoubtedly altered in PD patients $[2,3,17]-$ it is impossible to tease apart the contribution of the treatment and of the disease in this paradigm. A small number of studies have looked at metabolomics of peripheral fluids in PD [12-14], few of which include PD patients without L-dopa [1820]. Several studies have looked at plasma or urine metabolites in PD versus controls, and found similar results to those described here $[12,20,21,14,22,23,18]$. However, since these patients did not abstain from PD medication, these results are likely driven by PD treatment rather than PD pathology. This highlights a challenge facing these type of biomarker studies and underscores the need for longitudinal studies and creative ways to correct for treatment effects.

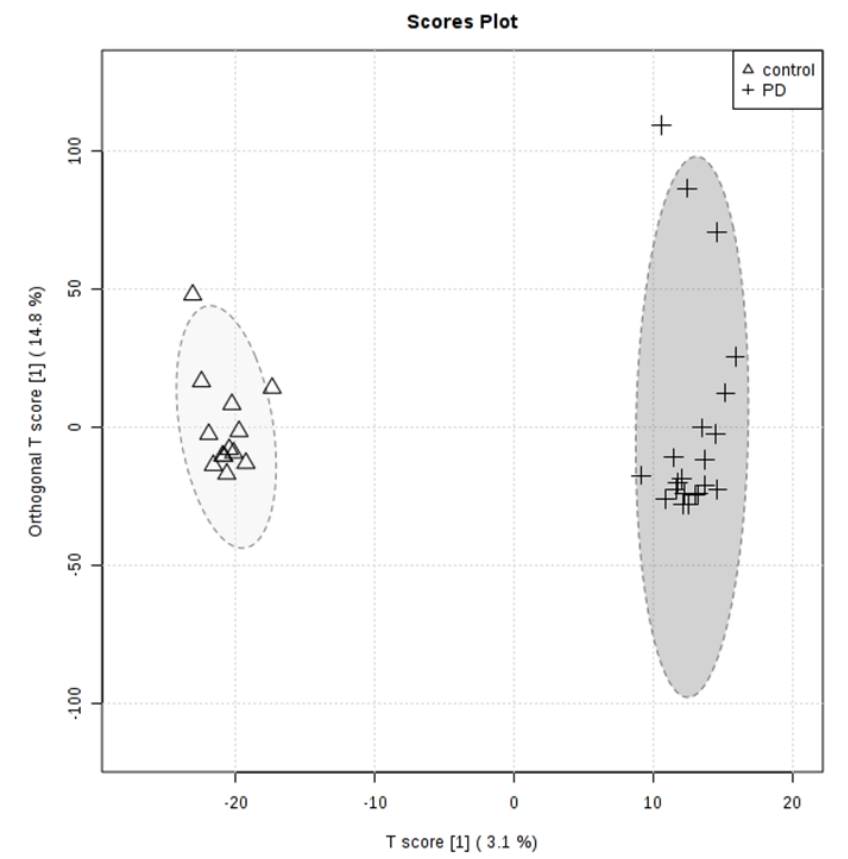

Fig 3. Orthogonal Partial Least Squares Discriminant Analysis (OPLS-DA). Clear separation between the PD and Control group were visible. 
bioRxiv preprint doi: https://doi.org/10.1101/306266; this version posted May 22, 2018. The copyright holder for this preprint (which was not certified by peer review) is the author/funder, who has granted bioRxiv a license to display the preprint in perpetuity. It is made available under aCC-BY-NC-ND 4.0 International license.

Pathways that correlate with L-dopa concentration

Pathways that are most different between PD and control patients
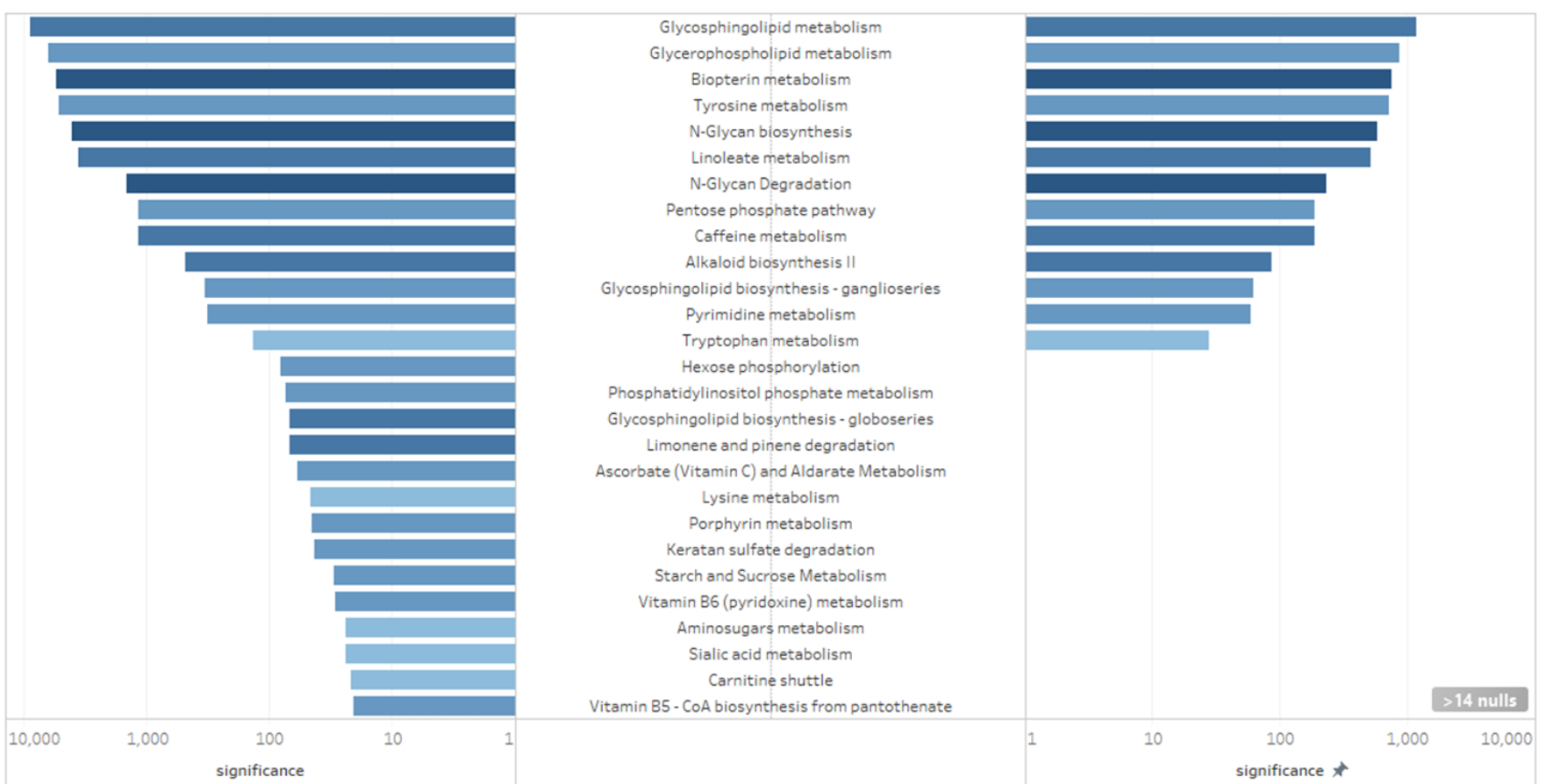

Fig 4. Altered metabolic pathways. Left, metabolic pathways that correlate with L-dopa concentration. Right, metabolic pathways that are most different between PD and control patients. The $x$-axis is degree of significance, calculated by $\log (1 /$ adjusted-p-value). Metabolic pathways with adjusted $p$-values greater than 0.05 were excluded from visualization. Color corresponds with the extent that the network was affected, where dark blue denotes that a large proportion of metabolites within the network were affected, and a light blue denotes that a relatively small proportion of metabolites within a network were affected.

\section{Peripheral markers of dopamine dynamics.}

Our analysis identified elevated levels of DOPAL in the plasma of PD patients compared to controls. DOPAL is a cytosolic product of dopamine that is metabolized by monoamine oxidase-A in the outer mitochondrial membrane [24]. DOPAL is a neurotoxin which selectively kills dopamine neurons [25-27]. Toxic DOPAL buildup due to insufficient sequestration by vesicular proteins has been hypothesized to be the precursor to dopamine cell death in PD pathogenesis [28,29]. It is possible that L-dopa treatment in our PD patient population mediated the elevated DOPAL content. However, while in the total patient population L-dopa dosage and DOPAL plasma concentration were associated $\left(\mathrm{r}^{2}=0.365\right)$, this correlation was absent when we restricted analysis to PD patients only. We were surprised to observe that DOPAL content differed between PD and control patients in the peripheral blood. The detection of DOPAL in plasma suggests that a test could be devised to measure the DOPAL:DA ratio as an indicator of vesicular dopamine function.

\section{Differences between PD and control plasma.}

Despite the confounding effect of L-dopa in this analysis, variations in harmalol and ganglioside GM2 (a metabolite of the glycosphingolipid pathway) associated with PD suggests additional biological changes were detected. Both were identified as elevated in control patient plasma compared to PD patients. To our knowledge, there is not a readily apparent biological mechanism through which PD medication might lower endogenous levels of either harmalol or ganglioside GM2. Therefore, these differences may be due to pathological or physiological differences between patients with and without PD diagnosis, rather than due to an effect of taking PD medication.

Harmalol is an indole beta-carboline alkaloid found in a variety of tissues, including brain, and in a variety of consumable plants, most notably in the leaves of tobacco plants [30-32]. Despite early therapeutic promise [33], studies demonstrating neurotoxic effects of beta-carbolines dampened clinical enthusiasm [34-36]. Later studies found that at low doses, betacarbolines can be neuroprotective, as demonstrated in PC12 cells
[37-39], primary cell culture [40], and in a rat model of PD [41]. Beta-carbolines, particularly harmalol and harmine, exert this effect at the surface of the mitochondrial membrane of dopaminergic cells, preventing oxidative damage from freeradicals [42].

Certainly, our findings that harmalol is elevated in plasma from control patients is exciting given the therapeutic potential of the alkaloid. It is unclear whether control patients display elevated concentrations of harmalol due to an elevated endogenous production of the chemical, or if their elevated harmalol levels are due to a history of consuming of harmalol-containing products. This difference could point to whether individuals who do not develop PD have an antioxidant-mediated protection factor, or whether they engage in habits that lower the risk of PD development. As beta-carboline alkaloids are found in tobacco plants and nicotine is known to independently reduce risk of developing PD [43], the elevated harmalol in control patients may be an artifact of the protective effect of smoking [44]. Although we cannot rule out the possibility, we do not believe it is likely that smoking drove the difference in harmalol in these patients. Concentration of plasma harmalol was not associated with plasma cotinine, a marker for smoking activity $\left(\mathrm{r}^{2}=0.073\right)$. Nonetheless, this does not rule out confounding entirely. For instance, participants in the study did not fast prior to serum collection, so it is plausible that dietary differences between cases and controls could account for some of the metabolic variability. Furthermore, while we have no knowledge of link between administration of Ldopa and changes in beta-carboline metabolism, this experiment cannot rule out the effect of PD drugs. In our sample of PD patients, L-dopa plasma concentration did weakly correlate with harmalol concentration $\left(\mathrm{r}^{2}=0.1901\right)$, while other studies have shown no correlation [45]. In addition, patients may or may not have been on some other medication that could have confounded the observed metabolic differences. Lastly, it is unknown whether blood plasma harmalol concentration correlates with harmalol levels in the brain. Elevated plasma levels of a compound do not always correspond with elevated levels in the brain [46], and there is evidence that PD patients actually show elevated beta-carboline levels in cerebrospinal fluid [45,47].

Gangliosides are a group of glycosphingolipid compounds that are especially common in the brain but are also 
bioRxiv preprint doi: https://doi.org/10.1101/306266; this version posted May 22, 2018. The copyright holder for this preprint (which was not certified by peer review) is the author/funder, who has granted bioRxiv a license to display the preprint in perpetuity. It is made available under aCC-BY-NC-ND 4.0 International license.

found in blood. Gangliosides have been implicated in a variety of neurodegenerative diseases [48]. We identified the ganglioside GM2 and the glycosphingolipid biosynthesis metabolic pathway in our pathway analysis. GM2 levels were lower in PD patients and correlated negatively with motor function as measured by UPDRS-III $(\mathrm{r}=-0.492)$. Our work implies that reduced peripheral GM2 could indicate central nervous system dysfunction. GM1 ganglioside is a potential therapeutic target for PD, and a recent study has further suggested GM1's disease-modifying effect on PD [49,50]. While GM1 has been extensively implicated in human $\mathrm{PD}$, the role of GM2 remains unclear. Other researchers have found that deletion of GM2/GD2 synthase- the enzyme that produces GM2 and GD2 gangliosides-causes a Parkinsonian phenotype, likely due to downstream effects on GM1 [51]. Furthermore, the pathological fibrillation of $\alpha$-synuclein, which is characteristic of PD, can be inhibited by GM2 (and even more so by GM1) [52]. As with harmalol, confounding-whether due to diet, L-DOPA administration, or some other factor-cannot be ruled out entirely. However, considered together, this analysis points towards ganglioside metabolism and GM2 in particular as potential biomarkers or therapeutic targets for future research.

\section{Conclusions.}

Our analysis shows that the presence of L-dopa widely influences the blood plasma metabolome in patients with PD. The influence of L-dopa may be more far-reaching than previously thought: our analysis shows that the effects of PD medications on the metabolome cannot simply be controlled for by removing direct metabolites of the medications. We caution other researchers to seek creative solutions when searching for potential diagnostic and/or prognostic biomarkers in future studies. Lastly, we highlight two metabolites of interest that were elevated in control versus PD serum, harmalol and the ganglioside metabolic pathway.

\section{Materials and Methods}

This study was approved by the human subject committee of Emory University. Subjects participated after written informed consent was obtained in accordance with the Declaration of Helsinki.

Study Population Characteristics. The plasma samples analyzed were collected from patients recruited through the Emory Movement Disorders Clinic and controls recruited in the Atlanta area from 20122013. The final study population contained 21 PD patients and 13 control patients. Demographic information was collected from all participants and is summarized in Table 1.

Clinical Data Collection. Clinical data was collected from all PD patients, including disease duration and daily L-dopa equivalent dosage of antiparkinsonian medications. All participants had UPDRS-III motor assessments by a fellowship-trained movement disorders neurologist [53]. All participants had cognitive assessments with the Montreal Cognitive Assessment (MOCA), and all participants completed the NonMotor Symptoms Questionnaire (NMSQ) [54,55]. Prior to plasma collection, patients were not required to fast nor to stop their PD medications. Exams and sample collections were typically conducted between 9 am and $11 \mathrm{am}$. Blood samples were collected in EDTA tubes,

1. Beitz JM. Parkinson's disease: a review. Front Biosci (Schol Ed). 2014;6: 6574.

2. Hornykiewicz $\mathrm{O}$. The metabolism of brain dopamine in human parkinsonism. Riv Patol Nerv Ment. 1970;91: 281-6.

3. Hornykiewicz $\mathrm{O}$. Biochemical aspects of Parkinson's disease. Neurology. 1998;51: S2-9. doi:10.1212/WNL.51.2_Suppl_2.S2

4. Braak H, Braak E. Neuropathological stageing of Alzheimer-related changes. Acta Neuropathol. 1991;82: 239-59.

5. Dauer W, Przedborski S. Parkinson's disease: mechanisms and models. Neuron. 2003;39: 889-909.

6. Birkmayer W, Hornykiewicz O. The L-dihydroxyphenylalanine (L-DOPA) effect in Parkinson's syndrome in man: On the pathogenesis and treatment of Parkinson akinesias. Arch Psychiatr Nervenkr Z Gesamte Neurol Psychiatr. 1962;203: 560-74.

7. Hornykiewicz O. L-DOPA. J Parkinsons Dis. IOS Press; 2017;7: S3-S10. doi:10.3233/JPD-179004

8. Alonso A, Marsal S, Julià A. Analytical methods in untargeted metabolomics: and immediately placed on ice. They were then transferred on ice an centrifuged at 2200 RPM for $15 \mathrm{~min}$. The plasma was transferred to a transport vial and frozen at $-80^{*} \mathrm{C}$ until mass spectrometry analysis. The time from sample collection to storage in the $-80^{*} \mathrm{C}$ freezer was less than 2 hours.

Mass spectrometry. Samples were prepared as previously described [12]. Briefly, $65 \mu \mathrm{L}$ of plasma was treated with $130 \mu \mathrm{L}$ of acetronitrile containing a mixture of 14 stable isotope standards. After mixing and incubation at $4^{\circ} \mathrm{C}$ for $30 \mathrm{~min}$, precipitated proteins were pelleted via centrifugation for $10 \mathrm{~min}$ at $16,100 \times \mathrm{g}$ at $4^{\circ} \mathrm{C}$. Supernatants were transferred to autosampler vials and stored at $4^{\circ} \mathrm{C}$ until analysis. Sample extracts were analyzed in triplicate by liquid chromatography-Fourier transform mass spectrometry (Dione Ultimate 3000;Thermo Scientific Q-Exactive HF High-Resolution Mass Spectrometer) with $10 \mathrm{uL}$ injection volume and a formic acid/acetonitrile gradient as described previously [56]. Electrospray ionization was used in the positive ion mode. Mass spectral data were collected at a resolution of 70,000 and scan range 85 to $1250 \mathrm{~m} / \mathrm{z}[11,57]$. Raw data files were extracted and aligned using apl CMS with modifications by xMSanalyzer with each feature uniquely defined by $m / z$ (mass-to-charge ratio), retention time, and sample ion intensity (integrated ion intensity for the peak).

Metabolomics data analysis. $R$ was used to analyze the metabolomics data. We first eliminated features which had greater than $35 \%$ variability within technical replicates. This reduced the data set from a total of $10,471 \mathrm{~m} / \mathrm{z}$ values to $9,071 \mathrm{~m} / \mathrm{z}$ values. Features detected only in PD cases were not removed from the dataset, as the potential measurement of exogenous compounds was one of the major aims of this study. Since a detection value of zero did not imply the absence of the feature, but rather that the amount of feature present was below the threshold of detection, we imputed half of the minimum detected value to all zero values. We then applied a generalized log transformation as described in MetaboAnalyst (55), which resulted in an approximately normal distribution.

To determine which features differed between PD versus control plasma, two-sample t-tests were conducted for each feature. P-values were adjusted using the FDR correction; features were sorted using the adjusted $p$-values. This analysis was performed using MetaboAnalyst software [58] and original $R$ code to verify results. To determine which metabolic pathways were most affected by PD drug treatments, we also performed a metabolome-wide association study restricted to PD patients wherein we calculated the correlations of the abundance of primary PD drug metabolite $(\mathrm{m} / \mathrm{z}=212.092$, retention time $=71)$ with every other metabolite feature, then created a network of metabolites that most significantly correlated with PD.

The degree of association between two variables was analyzed via linear correlation analysis and reporting the $r$ squared value and direction of association where appropriate.

Pathway analyses were performed in Mummichog [59]. The "force primary ion" option was chosen, ensuring that any predicted metabolites were present in at least their primary adduct $\left(\mathrm{M}+\mathrm{H}^{+}\right)$. A $p$ threshold of 0.05 was selected. Pathways identified in Mummichog were visualized in Cytoscape [60]. Identity of networks was visualized using Tableau (Seattle, Washington).

For orthogonal partial least squares-discriminant analysis (OPLSDA), the data was mean-centered prior to analysis $[61,62]$. OPLS-DA was performed and visualized both using $R$ and MetaboAnalyst tools.

Putative identities of metabolite features was determined via multiple parallel methods: a custom deconvolution and identification algorithm (Emory University, Atlanta, Georgia), xMSanalyzer [57], and manual lookup in various online metabolite databases (Human Metabolome Database, Kyoto Encyclopedia of Genes and Genome) $[63,64]$.

state of the art in 2015. Front Bioeng Biotechnol. Frontiers Media SA; 2015;3: 23. doi:10.3389/fbioe.2015.00023

9. Gowda GAN, Zhang S, Gu H, Asiago V, Shanaiah N, Raftery D. Metabolomics-based methods for early disease diagnostics. Expert Rev Mol Diagn. 2008;8: 617-33. doi:10.1586/14737159.8.5.617

10. Uppal K, Walker DI, Liu K, Li S, Go Y-M, Jones DP. Computational metabolomics: a framework for the million metabolome. Chem Res Toxicol. 2016;29: 1956-1975. doi:10.1021/acs.chemrestox.6b00179

11. Yu T, Park Y, Li S, Jones DP. Hybrid feature detection and information accumulation using high-resolution LC-MS metabolomics data. J Proteome Res. 2013;12: 1419-1427. doi:10.1021/pr301053d

12. Roede JR, Uppal K, Park Y, Lee K, Tran V, Walker D, et al. Serum metabolomics of slow vs. rapid motor progression Parkinson's disease: a pilot study. Cookson MR, editor. PLoS One. 2013;8: e77629. doi:10.1371/journal.pone.0077629

13. Chang $\mathrm{K}-\mathrm{H}$, Cheng $\mathrm{M}-\mathrm{L}$, Tang $\mathrm{H}-\mathrm{Y}$, Huang $\mathrm{C}-\mathrm{Y}, \mathrm{Wu} \mathrm{Y}-\mathrm{R}$, Chen $\mathrm{C}-\mathrm{M}$. Alternations of metabolic profile and kynurenine metabolism in the plasma 
bioRxiv preprint doi: https://doi.org/10.1101/306266; this version posted May 22, 2018. The copyright holder for this preprint (which was not certified by peer review) is the author/funder, who has granted bioRxiv a license to display the preprint in perpetuity. It is made available under aCC-BY-NC-ND 4.0 International license.

of Parkinson's Disease. Mol Neurobiol. Springer US; 2018; 1-10. doi:10.1007/s12035-017-0845-3

14. Luan H, Liu L-F, Tang Z, Zhang M, Chua K-K, Song J-X, et al. Comprehensive urinary metabolomic profiling and identification of potential noninvasive marker for idiopathic Parkinson's disease. Sci Rep. 2015;5: 13888. doi:10.1038/srep13888

15. Schymanski EL, Jeon J, Gulde R, Fenner K, Ruff M, Singer HP, et al. Identifying small molecules via high resolution mass spectrometry: Communicating Confidence. doi:10.1021/es5002105

16. Wiklund S, Johannson E, Sjostrom L, Mellerowicz E, Edlund U, Shockcor J, et al. Visualization of GC/TOF-MS-based metabolomics data for identification of biochemically interesting compounds using OPLS class models. Anal Chem. 2008; 115-122.

17. Pifl C, Rajput A, Reither H, Blesa J, Cavada C, Obeso JA, et al. Is Parkinson's disease a vesicular dopamine storage disorder? Evidence from a study in isolated synaptic vesicles of human and nonhuman primate striatum. J Neurosci. 2014;34: 8210-8. doi:10.1523/JNEUROSCI.5456-13.2014

18. Trupp $M$, Jonsson $P$, Ohrfelt A, Zetterberg $H$, Obudulu $O$, Malm L, et al. Metabolite and peptide levels in plasma and CSF differentiating healthy controls from patients with newly diagnosed Parkinson's disease. J Parkinsons Dis. 2014;4: 549-60. doi:10.3233/JPD-140389

19. Ahmed SS, Santosh W, Kumar S, Christlet HTT. Metabolic profiling of Parkinson's disease: evidence of biomarker from gene expression analysis and rapid neural network detection. J Biomed Sci. 2009;16: 63. doi:10.1186/1423-0127-16-63

20. Bogdanov M, Matson WR, Wang L, Matson T, Saunders-Pullman R, Bressman SS, et al. Metabolomic profiling to develop blood biomarkers for Parkinson's disease. Brain. Umetrics AB, Malmo, Sweden; 2008;131: 389396. doi:10.1093/brain/awm304

21. Luan H, Liu L-F, Meng N, Tang Z, Chua K-K, Chen L-L, et al. LC-MS-Based urinary metabolite signatures in idiopathic Parkinson's Disease. J Proteome Res. 2015;14: 467-478. doi:10.1021/pr500807t

22. Hatano T, Saiki S, Okuzumi A, Mohney RP, Hattori N. Identification of novel biomarkers for Parkinson's disease by metabolomic technologies. J Neurol Neurosurg Psychiatry. 2016;87: 295-301. doi:10.1136/jnnp-2014-309676

23. Johansen KK, Wang L, Aasly JO, White LR, Matson WR, Henchcliffe C, et al. Metabolomic profiling in LRRK2-related Parkinson's Disease. Cookson MR, editor. PLoS One. Public Library of Science; 2009;4: e7551. doi:10.1371/journal.pone.0007551

24. Eisenhofer G, Kopin IJ, Goldstein DS. Catecholamine Metabolism: A contemporary view with implications for physiology and medicine. Pharmacol Rev. 2004;56: 331-349. doi:10.1124/pr.56.3.1

25. Panneton WM, Kumar VB, Gan Q, Burke WJ, Galvin JE. The neurotoxicity of DOPAL: behavioral and stereological evidence for its role in Parkinson disease pathogenesis. Ginsberg SD, editor. PLoS One. 2010;5: e15251. doi:10.1371/journal.pone.0015251

26. Mattammal MB, Haring JH, Chung HD, Raghu G, Strong R. An endogenous dopaminergic neurotoxin: implication for Parkinson's disease. Neurodegeneration. 1995;4: 271-81.

27. Burke WJ, Li SW, Williams EA, Nonneman R, Zahm DS. 3,4Dihydroxyphenylacetaldehyde is the toxic dopamine metabolite in vivo: implications for Parkinson's disease pathogenesis. Brain Res. 2003;989: 205-13.

28. Goldstein DS, Sullivan P, Holmes C, Miller GW, Alter S, Strong R, et al. Determinants of buildup of the toxic dopamine metabolite DOPAL in Parkinson's disease. J Neurochem. 2013;126: 591-603. doi:10.1111/jnc.12345

29. Goldstein DS, Holmes C, Sullivan P, Mash DC, Sidransky E, Stefani A, et al. Deficient vesicular storage: A common theme in catecholaminergic neurodegeneration. Parkinsonism Relat Disord. 2015;21: 1013-1022. doi:10.1016/j.parkreldis.2015.07.009

30. Holmstedt B, Lindgren J. Chemical constituents and pharmacology of South American snuffs. Psychopharmacol Bull. 1967;4: 16.

31. Airaksinen MM, Kari I. Beta-carbolines, psychoactive compounds in the mammalian body. Part I: Occurrence, origin and metabolism. Med Biol. 1981;59: 21-34.

32. Moloudizargari M, Mikaili P, Aghajanshakeri S, Asghari MH, Shayegh J. Pharmacological and therapeutic effects of Peganum harmala and its main alkaloids. Pharmacogn Rev. 2013;7: 199-212. doi:10.4103/09737847.120524

33. Cooper HA, Gunn JA. Harmalol in the treatment of Parkinsonism. Lancet. Elsevier; 1931;218: 901-903. doi:10.1016/S0140-6736(01)08875-4

34. Cobuzzi RJ, Neafsey EJ, Collins MA. Differential cytotoxicities of N-methyl- beta-carbolinium analogues of MPP+ in PC12 cells: insights into potential neurotoxicants in Parkinson's disease. J Neurochem. 1994;62: 1503-10.

35. O'Hearn E, Molliver ME. Degeneration of Purkinje cells in parasagittal zones of the cerebellar vermis after treatment with ibogaine or harmaline. Neuroscience. 1993;55: 303-10.

36. Storch A, Hwang Y-I, Gearhart DA, Beach JW, Neafsey EJ, Collins MA, et al. Dopamine transporter-mediated cytotoxicity of beta-carbolinium derivatives related to Parkinson's disease: relationship to transporterdependent uptake. J Neurochem. 2004;89: 685-94. doi:10.1111/j.14714159.2004.02397.x

37. Kim DH, Jang YY, Han ES, Lee CS. Protective effect of harmaline and harmalol against dopamine- and 6-hydroxydopamine-induced oxidative damage of brain mitochondria and synaptosomes, and viability loss of PC12 cells. Eur J Neurosci. 2001;13: 1861-72.

38. Han Y-S, Kim J-M, Cho J-S, Lee CS, Kim D-E. Comparison of the protective effect of indole beta-carbolines and R-(-)-deprenyl against nitrogen speciesinduced cell death in experimental culture model of Parkinson's Disease. J Clin Neurol. 2005;1: 81-91. doi:10.3988/jcn.2005.1.1.81

39. Park TH, Kwon OS, Park SY, Han ES, Lee CS. N-methylated beta-carbolines protect PC12 cells from cytotoxic effect of MPP+ by attenuation of mitochondrial membrane permeability change. Neurosci Res. 2003;46: 349-58.

40. Polanski W, Enzensperger C, Reichmann H, Gille G. The exceptional properties of 9-methyl- $\beta$-carboline: stimulation, protection and regeneration of dopaminergic neurons coupled with anti-inflammatory effects. J Neurochem. 2010;113: no-no. doi:10.1111/j.14714159.2010.06725.x

41. Wernicke C, Hellmann J, Zieba B, Kuter K, Ossowska K, Frenzel M, et al. 9Methyl-beta-carboline has restorative effects in an animal model of Parkinson's disease. Pharmacol Rep. 62: 35-53.

42. Pari K, Sundari CS, Chandani S, Balasubramanian D. beta-carbolines that accumulate in human tissues may serve a protective role against oxidative stress. J Biol Chem. 2000;275: 2455-62.

43. Dunn AR, Stout KA, Ozawa M, Lohr KM, Hoffman CA, Bernstein Al, et al. Synaptic vesicle glycoprotein $2 \mathrm{C}$ (SV2C) modulates dopamine release and is disrupted in Parkinson disease. Proc Natl Acad Sci. 2017;114: E2253-E2262. doi:10.1073/pnas.1616892114

44. Soto-Otero R, Méndez-Alvarez E, Riguera-Vega R, Quiñoá-Cabana E, Sánchez-Sellero I, López-Rivadulla Lamas M. Studies on the interaction between 1,2,3,4-tetrahydro-beta-carboline and cigarette smoke: a potential mechanism of neuroprotection for Parkinson's disease. Brain Res. 1998;802: 155-62.

45. Kuhn W, Müller T, Große H, Rommelspacher H. Elevated levels of harman and norharman in cerebrospinal fluid of Parkinsonian patients. J Neural Transm. 1996;103: 1435-1440. doi:10.1007/BF01271257

46. Grimmer T, Riemenschneider M, Förstl $H$, Henriksen $G$, Klunk WE, Mathis $\mathrm{CA}$, et al. Beta amyloid in Alzheimer's Disease: Increased deposition in brain Is reflected in reduced concentration in cerebrospinal fluid. Biol Psychiatry. Georg Thieme Verlag, Stuttgart, Germany; 2009;65: 927-934. doi:10.1016/j.biopsych.2009.01.027

47. Matsubara K, Kobayashi S, Kobayashi Y, Yamashita K, Koide H, Hatta M, et al. beta-Carbolinium cations, endogenous MPP+ analogs, in the lumbar cerebrospinal fluid of patients with Parkinson's disease. Neurology. 1995;45: 2240-5.

48. Kolter T. Ganglioside Biochemistry. ISRN Biochem. 2012;2012: 1-36. doi:10.5402/2012/506160

49. Bisel B, Pavone FS, Calamai M. GM1 and GM2 gangliosides: recent developments. Biomol Concepts. 2014;5: 87-93. doi:10.1515/bmc-20130039

50. Schneider JS, Cambi F, Gollomp SM, Kuwabara H, Brašić JR, Leiby B, et al. GM1 ganglioside in Parkinson's disease: Pilot study of effects on dopamine transporter binding. J Neurol Sci. 2015;356: 118-23. doi:10.1016/j.jns.2015.06.028

51. Wu G, Lu Z-H, Kulkarni N, Amin R, Ledeen RW. Mice lacking major brain gangliosides develop parkinsonism. Neurochem Res. 2011;36: 1706-14. doi:10.1007/s11064-011-0437-y

52. Martinez Z, Zhu M, Han S, Fink AL. GM1 specifically interacts with alphasynuclein and inhibits fibrillation. Biochemistry. 2007;46: 1868-77. doi:10.1021/bi061749a

53. Goetz CG, Fahn S, Martinez-Martin P, Poewe W, Sampaio C, Stebbins GT, et al. Movement Disorder Society-sponsored revision of the Unified Parkinson's Disease Rating Scale (MDS-UPDRS): Process, format, and clinimetric testing plan. Mov Disord. 2007;22: 41-47. 
bioRxiv preprint doi: https://doi.org/10.1101/306266; this version posted May 22, 2018. The copyright holder for this preprint (which was not certified by peer review) is the author/funder, who has granted bioRxiv a license to display the preprint in perpetuity. It is made available under aCC-BY-NC-ND 4.0 International license.

doi:10.1002/mds.21198

54. Nasreddine ZS, Phillips NA, BÃ@dirian V, Charbonneau S, Whitehead V, Collin I, et al. The Montreal Cognitive Assessment, MoCA: A brief screening tool for mild cognitive impairment. J Am Geriatr Soc. 2005;53: 695-699. doi:10.1111/j.1532-5415.2005.53221.x

55. Chaudhuri KR, Martinez-Martin P, Schapira AHV, Stocchi F, Sethi K, Odin P, et al. International multicenter pilot study of the first comprehensive selfcompleted nonmotor symptoms questionnaire for Parkinson's disease: The NMSQuest study. Mov Disord. 2006;21: 916-923. doi:10.1002/mds.20844

56. Walker DI, Pennell KD, Uppal K, Xia X, Hopke PK, Utell MJ, et al. Pilot metabolome-wide association study of benzo(a)pyrene in serum from military personnel. J Occup Environ Med. 2016;58: S44-52. doi:10.1097/JOM.0000000000000772

57. Uppal K, Soltow QA, Strobel FH, Pittard WS, Gernert KM, Yu T, et al. xMSanalyzer: automated pipeline for improved feature detection and downstream analysis of large-scale, non-targeted metabolomics data. BMC Bioinformatics. 2013;14: 15. doi:10.1186/1471-2105-14-15

58. Xia J, Wishart DS, Xia J, Wishart DS. Using MetaboAnalyst 3.0 for Comprehensive metabolomics data analysis. Current Protocols in Bioinformatics. Hoboken, NJ, USA: John Wiley \& Sons, Inc.; 2016. p. 14.10.114.10.91. doi:10.1002/cpbi.11
59. Li S, Park Y, Duraisingham S, Strobel FH, Khan N, Soltow QA, et al. Predicting network activity from high throughput metabolomics. Ouzounis CA, editor. PLoS Comput Biol. 2013;9: e1003123. doi:10.1371/journal.pcbi.1003123

60. Shannon P, Markiel A, Ozier O, Baliga NS, Wang JT, Ramage D, et al. Cytoscape: a software environment for integrated models of biomolecular interaction networks. Genome Res. Cold Spring Harbor Laboratory Press; 2003;13: 2498-504. doi:10.1101/gr.1239303

61. Vinaixa M, Samino S, Saez I, Duran J, Guinovart JJ, Yanes O. A guideline to univariate statistical analysis for LC/MS-based untargeted metabolomicsderived data. Metabolites. Multidisciplinary Digital Publishing Institute (MDPI); 2012;2: 775-95. doi:10.3390/metabo2040775

62. van den Berg RA, Hoefsloot HC, Westerhuis JA, Smilde AK, van der Werf MJ. Centering, scaling, and transformations: improving the biological information content of metabolomics data. BMC Genomics. 2006;7: 142. doi:10.1186/1471-2164-7-142

63. Wishart DS, Jewison T, Guo AC, Wilson M, Knox C, Liu Y, et al. HMDB 3.0The Human Metabolome Database in 2013. Nucleic Acids Res. Oxford University Press; 2012;41: D801-D807. doi:10.1093/nar/gks1065

64. Tanabe M, Kanehisa M. Using the KEGG Database Resource. Current Protocols in Bioinformatics. Hoboken, NJ, USA: John Wiley \& Sons, Inc.; 2012. p. Unit1.12. doi:10.1002/0471250953.bi0112s38 
bioRxiv preprint doi: https://doi.org/10.1101/306266; this version posted May 22, 2018. The copyright holder for this preprint (which was not certified by peer review) is the author/funder, who has granted bioRxiv a license to display the preprint in perpetuity. It is made available under aCC-BY-NC-ND 4.0 International license.

\begin{tabular}{|c|c|}
\hline Metabolic Pathway & Metabolite Names \\
\hline $\begin{array}{l}\text { Glycosphingolipid } \\
\text { metabolism }\end{array}$ & $\begin{array}{l}\text { Choline phosphate; Phosphorylcholine; Phosphocholine; D-Glucose; Grape sugar; Sphinganine; Dihydrosphingosine; Psychosine; } \\
\text { Galactosylsphingosine; N-Acetylneuraminate; N-Acetylneuraminic acid; 5-Acetamido-3,5-dideoxy-D-glycero-D-galacto-2- } \\
\text { nonulosonic acid; CMP; Cytidine-5'-monophosphate; Sphingosine; Sphingenine; Sphingoid; 3-Dehydrosphinganine; beta-D- } \\
\text { Galactose }\end{array}$ \\
\hline $\begin{array}{l}\text { Glycerophospholipid } \\
\text { metabolism }\end{array}$ & $\begin{array}{l}\text { Choline phosphate; Phosphorylcholine; Phosphocholine; Glycerol; Glycerin; 1,2,3-Trihydroxypropane; Acetylcholine; Sphinganine; } \\
\text { Dihydrosphingosine; myo-Inositol; D-myo-Inositol; 1D-myo-Inositol; L-myo-Inositol; 1L-myo-Inositol; meso-Inositol; Inositol; } \\
\text { Dambose; Cyclohexitol; Meat sugar; CTP; Cytidine 5'-triphosphate; Linoleate; Linoleic acid; (9Z,12Z)-Octadecadienoic acid; 9- } \\
\text { cis,12-cis-Octadecadienoate; CMP; Cytidine-5'-monophosphate; (5Z,8Z,11Z,14Z)-Icosatetraenoic acid; Arachidonate; Arachidonic } \\
\text { acid; Sphingosine; Sphingenine; Sphingoid; Inositol 1-phosphate; myo-Inositol 1-phosphate; 1D-myo-Inositol 1-phosphate; D-myo- } \\
\text { Inositol 1-phosphate; 1D-myo-Inositol 1-monophosphate }\end{array}$ \\
\hline Biopterin metabolism & $\begin{array}{l}\text { L-Phenylalanine; L-Tyrosine; (S)-3-(p-Hydroxyphenyl)alanine; (S)-2-Amino-3-(p-hydroxyphenyl)propionic acid; } \\
\text { Tetrahydrobiopterin; 5,6,7,8-Tetrahydrobiopterin; 6-Pyruvoyltetrahydropterin; 6-(1,2-Dioxopropyl)-5,6,7,8-tetrahydropterin; } \\
\text { quinonoid dihydrobiopterin }\end{array}$ \\
\hline Tyrosine metabolism & $\begin{array}{l}\text { Phenethylamine; Tetrahydrobiopterin; 5,6,7,8-Tetrahydrobiopterin; L-Phenylalanine; Ascorbate; Ascorbic acid; L-Ascorbate; L- } \\
\text { Ascorbic acid; L-Tyrosine; (S)-3-(p-Hydroxyphenyl)alanine; (S)-2-Amino-3-(p-hydroxyphenyl)propionic acid; Dopamine; 4-(2- } \\
\text { Aminoethyl)-1,2-benzenediol; 4-(2-Aminoethyl)benzene-1,2-diol; 3,4-Dihydroxyphenylacetaldehyde; 3-O-methyldopa }\end{array}$ \\
\hline $\mathrm{N}$-Glycan biosynthesis & $\begin{array}{l}\text { D-Mannose; Mannose; Seminose; CMP; Cytidine-5'-monophosphate; CTP; Cytidine 5'-triphosphate; Dolichyl phosphate D- } \\
\text { mannose; D-Glucose; Grape sugar; Dextrose }\end{array}$ \\
\hline Linoleate metabolism & $\begin{array}{l}\text { Ascorbate; Ascorbic acid; L-Ascorbate; L-Ascorbic acid; Linoleate; Linoleic acid; (9Z,12Z)-Octadecadienoic acid; 9-cis,12-cis- } \\
\text { Octadecadienoate; 9(S)-HPODE; 9(S)-HPOD; (9Z,11E)-(13S)-13-Hydroperoxyoctadeca-9,11-dienoic acid; (9Z,11E)-(13S)-13- } \\
\text { Hydroperoxyoctadeca-9,11-dienoate; 13(S)-HPODE; 13S-Hydroperoxy-9Z,11E-octadecadienoic acid }\end{array}$ \\
\hline N-Glycan Degradation & $\begin{array}{l}\text { D-Mannose; Mannose; Seminose; N-Acetylneuraminate; N-Acetylneuraminic acid; 5-Acetamido-3,5-dideoxy-D-glycero-D-galacto- } \\
\text { 2-nonulosonic acid; D-Galactose }\end{array}$ \\
\hline $\begin{array}{l}\text { Pentose phosphate } \\
\text { pathway }\end{array}$ & $\begin{array}{l}\text { D-Sedoheptulose 1,7-bisphosphate; Deoxyribose; 2-Deoxy-D-erythro-pentose; Thyminose; D-Fructose 6-phosphate; D-Fructose 6- } \\
\text { phosphoric acid; Sedoheptulose 1-phosphate; Sedoheptulose 7-phosphate; D-Glucose 6-phosphate; Glucose 6-phosphate; D- } \\
\text { Sedoheptulose 7-phosphate; beta-D-Fructose 6-phosphate }\end{array}$ \\
\hline Caffeine metabolism & 1,7-Dimethylxanthine; 1-Methylxanthine \\
\hline Alkaloid biosynthesis II & Benzoate; Benzoic acid; Benzenecarboxylic acid; Phenylformic acid; N-Methylputrescine \\
\hline $\begin{array}{l}\text { Glycosphingolipid } \\
\text { biosynthesis - } \\
\text { ganglioseries }\end{array}$ & CMP; Cytidine-5'-monophosphate; Chondroitin; D-Galactose\$Galactose \\
\hline Pyrimidine metabolism & $\begin{array}{l}\text { Deoxyribose; 2-Deoxy-D-erythro-pentose; Thyminose; \$dTMP; Thymidine 5'-phosphate; Deoxythymidine 5'-phosphate; } \\
\text { Thymidylic acid; 5'-Thymidylic acid; Thymidine monophosphate; Deoxythymidylic acid; dUMP; Deoxyuridylic acid; Deoxyuridine } \\
\text { monophosphate; Deoxyuridine 5'-phosphate; 2'-Deoxyuridine 5'-phosphate\$D-Glucose 1-phosphate; alpha-D-Glucose 1- } \\
\text { phosphate; Cori ester; 5,6-Dihydrouracil; 2,4(1H,3H)-Pyrimidinedione, dihydro-; Dihydrouracile; Dihydrouracil; 5,6-Dihydro-2,4- } \\
\text { dihydroxypyrimidine; Dihydrofolate; Dihydrofolic acid; 7,8-Dihydrofolate; 7,8-Dihydrofolic acid; CTP; Cytidine 5'-triphosphate; } \\
\text { CMP; Cytidine-5'-monophosphate; 2-Deoxy-D-ribose 1-phosphate; dGTP; 2'-Deoxyguanosine 5'-triphosphate; Deoxyguanosine 5'- } \\
\text { triphosphate; dUDP; 2'-Deoxyuridine 5'-diphosphate }\end{array}$ \\
\hline Tryptophan metabolism & $\begin{array}{l}\text { L-Tryptophan; Tryptophan; Indole-3-acetaldehyde; 2-(Indol-3-yl)acetaldehyde; 3-Hydroxyanthranilate; Indolepyruvate; } \\
\text { Indolepyruvic acid; (Indol-3-yl)pyruvate; Indole-3-pyruvate; Tetrahydrobiopterin; 5,6,7,8-Tetrahydrobiopterin; 4,6- } \\
\text { Dihydroxyquinoline; Quinoline-4,6-diol }\end{array}$ \\
\hline
\end{tabular}

Supplementary Table 1. 13 metabolic pathways identified as significantly different between PD patients and control patients. Mummichog software identified metabolic pathways that are most likely to be different between the PD and control patients. Identities of compounds found within these pathways are also listed. 
bioRxiv preprint doi: https://doi.org/10.1101/306266; this version posted May 22, 2018. The copyright holder for this preprint (which was not certified by peer review) is the author/funder, who has granted bioRxiv a license to display the preprint in perpetuity. It is made available under aCC-BY-NC-ND 4.0 International license.

\begin{tabular}{|c|c|}
\hline $\begin{array}{l}\text { Metabolic } \\
\text { Pathway }\end{array}$ & Metabolite Names \\
\hline $\begin{array}{l}\text { Glycosphingolipid } \\
\text { metabolism }\end{array}$ & $\begin{array}{l}\text { Choline phosphate; Phosphorylcholine; Phosphocholine; D-Glucose; Grape sugar; Sphinganine; Dihydrosphingosine; Psychosine; } \\
\text { Galactosylsphingosine; N-Acetylneuraminate; N-Acetylneuraminic acid; 5-Acetamido-3,5-dideoxy-D-glycero-D-galacto-2- } \\
\text { nonulosonic acid; CMP; Cytidine-5'-monophosphate; Sphingosine; Sphingenine; Sphingoid; 3-Dehydrosphinganine; beta-D- } \\
\text { Galactose }\end{array}$ \\
\hline $\begin{array}{l}\text { Glycerophospholipid } \\
\text { metabolism }\end{array}$ & $\begin{array}{l}\text { Choline phosphate; Phosphorylcholine; Phosphocholine; Glycerol; Glycerin; 1,2,3-Trihydroxypropane; Acetylcholine; Sphinganine; } \\
\text { Dihydrosphingosine; myo-Inositol; D-myo-Inositol; 1D-myo-Inositol; L-myo-Inositol; 1L-myo-Inositol; meso-Inositol; Inositol; } \\
\text { Dambose; Cyclohexitol; Meat sugar; CTP; Cytidine 5'-triphosphate; Linoleate; Linoleic acid; (9Z,12Z)-Octadecadienoic acid; 9-cis,12- } \\
\text { cis-Octadecadienoate; CMP; Cytidine-5'-monophosphate; (5Z,8Z,11Z,14Z)-Icosatetraenoic acid; Arachidonate; Arachidonic acid; } \\
\text { Sphingosine; Sphingenine; Sphingoid; Inositol 1-phosphate; myo-Inositol 1-phosphate; 1D-myo-Inositol 1-phosphate; D-myo- } \\
\text { Inositol 1-phosphate; 1D-myo-Inositol 1-monophosphate }\end{array}$ \\
\hline Biopterin metabolism & $\begin{array}{l}\text { L-Phenylalanine; L-Tyrosine; (S)-3-(p-Hydroxyphenyl)alanine; (S)-2-Amino-3-(p-hydroxyphenyl)propionic acid; Tetrahydrobiopterin; } \\
\text { 5,6,7,8-Tetrahydrobiopterin; 6-Pyruvoyltetrahydropterin; 6-(1,2-Dioxopropyl)-5,6,7,8-tetrahydropterin; quinonoid } \\
\text { dihydrobiopterin }\end{array}$ \\
\hline Tyrosine metabolism & $\begin{array}{l}\text { Phenethylamine; Tetrahydrobiopterin; 5,6,7,8-Tetrahydrobiopterin; L-Phenylalanine; Ascorbate; Ascorbic acid; L-Ascorbate; L- } \\
\text { Ascorbic acid; L-Tyrosine; (S)-3-(p-Hydroxyphenyl)alanine; (S)-2-Amino-3-(p-hydroxyphenyl)propionic acid; Dopamine; 4-(2- } \\
\text { Aminoethyl)-1,2-benzenediol; 4-(2-Aminoethyl)benzene-1,2-diol; 3,4-Dihydroxyphenylacetaldehyde; 3-O-methyldopa }\end{array}$ \\
\hline N-Glycan biosynthesis & $\begin{array}{l}\text { D-Mannose; Mannose; Seminose; CMP; Cytidine-5'-monophosphate; CTP; Cytidine 5'-triphosphate; Dolichyl phosphate D- } \\
\text { mannose; D-Glucose; Grape sugar; Dextrose }\end{array}$ \\
\hline Linoleate metabolism & $\begin{array}{l}\text { Ascorbate; Ascorbic acid; L-Ascorbate; L-Ascorbic acid; Linoleate; Linoleic acid; (9Z,12Z)-Octadecadienoic acid; 9-cis,12-cis- } \\
\text { Octadecadienoate; 9(S)-HPODE; 9(S)-HPOD; (9Z,11E)-(13S)-13-Hydroperoxyoctadeca-9,11-dienoic acid; (9Z,11E)-(13S)-13- } \\
\text { Hydroperoxyoctadeca-9,11-dienoate; 13(S)-HPODE; 13S-Hydroperoxy-9Z,11E-octadecadienoic acid }\end{array}$ \\
\hline N-Glycan Degradation & $\begin{array}{l}\text { D-Mannose; Mannose; Seminose; Carubinose\$N-Acetylneuraminate; N-Acetylneuraminic acid; 5-Acetamido-3,5-dideoxy-D- } \\
\text { glycero-D-galacto-2-nonulosonic acid; Neu5Ac\$D-Galactose }\end{array}$ \\
\hline $\begin{array}{l}\text { Pentose phosphate } \\
\text { pathway }\end{array}$ & $\begin{array}{l}\text { D-Sedoheptulose 1,7-bisphosphate; Deoxyribose; 2-Deoxy-D-erythro-pentose; Thyminose; D-Fructose 6-phosphate; D-Fructose 6- } \\
\text { phosphoric acid; Sedoheptulose 1-phosphate; Sedoheptulose 7-phosphate; D-Glucose 6-phosphate; Glucose 6-phosphate; D- } \\
\text { Sedoheptulose 7-phosphate; beta-D-Fructose 6-phosphate }\end{array}$ \\
\hline Caffeine metabolism & 1,7-Dimethylxanthine; 1-Methylxanthine \\
\hline Alkaloid biosynthesis II & Benzoate; Benzoic acid; Benzenecarboxylic acid; Phenylformic acid; N-Methylputrescine \\
\hline $\begin{array}{l}\text { Glycosphingolipid } \\
\text { biosynthesis - } \\
\text { ganglioseries }\end{array}$ & CMP; Cytidine-5'-monophosphate; Chondroitin; Galactose \\
\hline Pyrimidine metabolism & $\begin{array}{l}\text { Deoxyribose; 2-Deoxy-D-erythro-pentose; Thyminose; \$dTMP; Thymidine 5'-phosphate; Deoxythymidine 5'-phosphate; Thymidylic } \\
\text { acid; 5'-Thymidylic acid; Thymidine monophosphate; Deoxythymidylic acid; dUMP; Deoxyuridylic acid; Deoxyuridine } \\
\text { monophosphate; Deoxyuridine 5'-phosphate; 2'-Deoxyuridine 5'-phosphate\$D-Glucose 1-phosphate; alpha-D-Glucose 1- } \\
\text { phosphate; Cori ester; 5,6-Dihydrouracil; 2,4(1H,3H)-Pyrimidinedione, dihydro-; Dihydrouracile; Dihydrouracil; 5,6-Dihydro-2,4- } \\
\text { dihydroxypyrimidine; Dihydrofolate; Dihydrofolic acid; 7,8-Dihydrofolate; 7,8-Dihydrofolic acid; CTP; Cytidine 5'-triphosphate; } \\
\text { CMP; Cytidine-5'-monophosphate; 2-Deoxy-D-ribose 1-phosphate; dGTP; 2'-Deoxyguanosine 5'-triphosphate; Deoxyguanosine 5'- } \\
\text { triphosphate; dUDP; 2'-Deoxyuridine 5'-diphosphate }\end{array}$ \\
\hline Tryptophan metabolism & $\begin{array}{l}\text { L-Tryptophan; Tryptophan; Indole-3-acetaldehyde; 2-(Indol-3-yl)acetaldehyde; 3-Hydroxyanthranilate; Indolepyruvate; } \\
\text { Indolepyruvic acid; (Indol-3-yl)pyruvate; Tetrahydrobiopterin; 4,8-Dihydroxyquinoline; 4,6-Dihydroxyquinoline; Quinoline-4,6-diol }\end{array}$ \\
\hline Hexose phosphorylation & $\begin{array}{l}\text { D-Mannose; Mannose; Seminose; cis-beta-D-Glucosyl-2-hydroxycinnamate; -Fructose 6-phosphate; D-Fructose 6-phosphoric acid; } \\
\text { D-Glucose; Grape sugar; D-Glucose 6-phosphate; Glucose 6-phosphate; Robison ester\$D-Fructose; Levulose; Fruit sugar; D- } \\
\text { arabino-Hexulose }\end{array}$ \\
\hline $\begin{array}{l}\text { Phosphatidylinositol } \\
\text { phosphate metabolism }\end{array}$ & $\begin{array}{l}\text { Glycerol; Glycerin; 1,2,3-Trihydroxypropane; Dolichyl phosphate D-mannose; myo-Inositol; D-myo-Inositol; 1D-myo-Inositol; L- } \\
\text { myo-Inositol; 1L-myo-Inositol; meso-Inositol; Inositol; Dambose; Cyclohexitol; Meat sugar; Inositol 1-phosphate; myo-Inositol 1- } \\
\text { phosphate; 1D-myo-Inositol 1-phosphate; D-myo-Inositol 1-phosphate; CMP; Cytidine-5'-monophosphate; D-myo-Inositol 1,4,5- } \\
\text { trisphosphate; 1D-myo-Inositol 1,4,5-trisphosphate; Inositol 1,4,5-trisphosphate; 1D-myo-Inositol 1,3,4-trisphosphate; D-myo- } \\
\text { Inositol 1,3,4-trisphosphate; myo-Inositol 4-phosphate; D-myo-Inositol 4-phosphate; 1D-myo-Inositol 4-phosphate; 1D-myo- } \\
\text { Inositol 4-monophosphate; D-Glucose 6-phosphate; Glucose 6-phosphate; 1D-myo-Inositol 3-phosphate; D-myo-Inositol 3- } \\
\text { phosphate; myo-Inositol 3-phosphate; Inositol 3-phosphate; 1D-myo-Inositol 3-monophosphate; D-myo-Inositol 3- } \\
\text { monophosphate; myo-Inositol 3-monophosphate; Inositol 3-monophosphate; 1L-myo-Inositol 1-phosphate; L-myo-Inositol 1- } \\
\text { phosphate }\end{array}$ \\
\hline $\begin{array}{l}\text { Limonene and pinene } \\
\text { degradation }\end{array}$ & Perillyl alcohol; (-)-Perillyl alcohol; p-Mentha-1,8-dien-7-ol; Perillyl aldehyde; Perillaldehyde \\
\hline $\begin{array}{l}\text { Glycosphingolipid } \\
\text { biosynthesis - globoseries }\end{array}$ & CMP; Cytidine-5'-monophosphate; alpha-D-Galactose \\
\hline $\begin{array}{l}\text { Ascorbate (Vitamin C) and } \\
\text { Aldarate Metabolism }\end{array}$ & $\begin{array}{l}\text { D-Glucarate; D-Glucaric acid; L-Gularic acid; d-Saccharic acid; Ascorbate; Ascorbic acid; L-Ascorbate; L-Ascorbic acid; D-glucurono- } \\
\text { 6,3-lactone }\end{array}$ \\
\hline Lysine metabolism & $\begin{array}{l}\text { L-Pipecolate; Pipecolinic acid; Pipecolic acid; 2-Piperidinecarboxylic acid\$Dihydrolipoamide; L-2-Aminoadipate; L-alpha- } \\
\text { Aminoadipate; L-alpha-Aminoadipic acid; L-2-Aminoadipic acid; L-2-Aminohexanedioate }\end{array}$ \\
\hline Porphyrin metabolism & $\begin{array}{l}\text { Ascorbate; Ascorbic acid; L-Ascorbate; L-Ascorbic acid; 5-Aminolevulinate; 5-Amino-4-oxopentanoate; 2-Amino-3-oxoadipate; 2- } \\
\text { Amino-3-oxohexanedioic acid }\end{array}$ \\
\hline $\begin{array}{l}\text { Keratan sulfate } \\
\text { degradation }\end{array}$ & N-AcetyIneuraminate; N-Acetylneuraminic acid; 5-Acetamido-3,5-dideoxy-D-glycero-D-galacto-2-nonulosonic acid; D-Galactose \\
\hline $\begin{array}{l}\text { Starch and Sucrose } \\
\text { Metabolism }\end{array}$ & lucose 1-phosphate; alpha-D-Glucose 1-phosphate; Cori ester; D-Glucose; Grape sugar; Dextrose \\
\hline
\end{tabular}


bioRxiv preprint doi: https://doi.org/10.1101/306266; this version posted May 22, 2018. The copyright holder for this preprint (which was not certified by peer review) is the author/funder, who has granted bioRxiv a license to display the preprint in perpetuity. It is made available under aCC-BY-NC-ND 4.0 International license.

\begin{tabular}{|l|l|}
\hline $\begin{array}{l}\text { Vitamin B6 (pyridoxine) } \\
\text { metabolism }\end{array}$ & Pyridoxine phosphate; Pyridoxine 5-phosphate; Pyridoxine 5'-phosphate \\
\hline Aminosugars metabolism & $\begin{array}{l}\text { D-Fructose 6-phosphate; D-Fructose 6-phosphoric acid; Cytidine 5'-triphosphate; N-Acetylneuraminate; N-Acetylneuraminic acid; } \\
\text { 5-Acetamido-3,5-dideoxy-D-glycero-D-galacto-2-nonulosonic acid; CMP; Cytidine-5'-monophosphate; N-Glycoloyl-neuraminate; N- } \\
\text { Glycolylneuraminate; NeuNGc }\end{array}$ \\
\hline Sialic acid metabolism & $\begin{array}{l}\text { Glycerol; Glycerin; 1,2,3-Trihydroxypropane; myo-Inositol; D-myo-Inositol; 1D-myo-Inositol; L-myo-Inositol; 1L-myo-Inositol; meso- } \\
\text { Inositol; Inositol; Dambose; Cyclohexitol; Meat sugar; N-Acetylneuraminate; N-Acetylneuraminic acid; 5-Acetamido-3,5-dideoxy-D- } \\
\text { glycero-D-galacto-2-nonulosonic acid; CMP; Cytidine-5'-monophosphate; 1D-myo-Inositol 3-phosphate; D-myo-Inositol 3- } \\
\text { phosphate; myo-Inositol 3-phosphate; Inositol 3-phosphate; 1D-myo-Inositol 3-monophosphate; D-myo-Inositol 3- } \\
\text { monophosphate; myo-Inositol 3-monophosphate; Inositol 3-monophosphate; 1L-myo-Inositol 1-phosphate; myo-Inositol 4- } \\
\text { phosphate; D-myo-Inositol 4-phosphate; 1D-myo-Inositol 4-phosphate; 1D-myo-Inositol 4-monophosphate; Inositol 1-phosphate; } \\
\text { myo-Inositol 1-phosphate; 1D-myo-Inositol 1-phosphate; D-myo-Inositol 1-phosphate; 1D-myo-Inositol 1-monophosphate }\end{array}$ \\
\hline Carnitine shuttle & \begin{tabular}{l} 
octadecenoyl carnitine \\
\hline $\begin{array}{l}\text { Vitamin B5 - CoA } \\
\text { biosynthesis from } \\
\text { pantothenate }\end{array}$
\end{tabular}$\quad$ CTP; Cytidine 5'-triphosphate; Pantetheine; (R)-Pantetheine \\
\hline
\end{tabular}

Supplementary Table 2. 27 metabolic pathways identified as correlated with L-DOPA. Mummichog software identified metabolic pathways that are strongly associated with the presence of L-DOPA. Identities of compounds found within these pathways are also listed. 
bioRxiv preprint doi: https://doi.org/10.1101/306266; this version posted May 22, 2018. The copyright holder for this preprint (which was not certified by peer review) is the author/funder, who has granted bioRxiv a license to display the preprint in perpetuity. It is made available under aCC-BY-NC-ND 4.0 International license.

\section{Scores Plot}

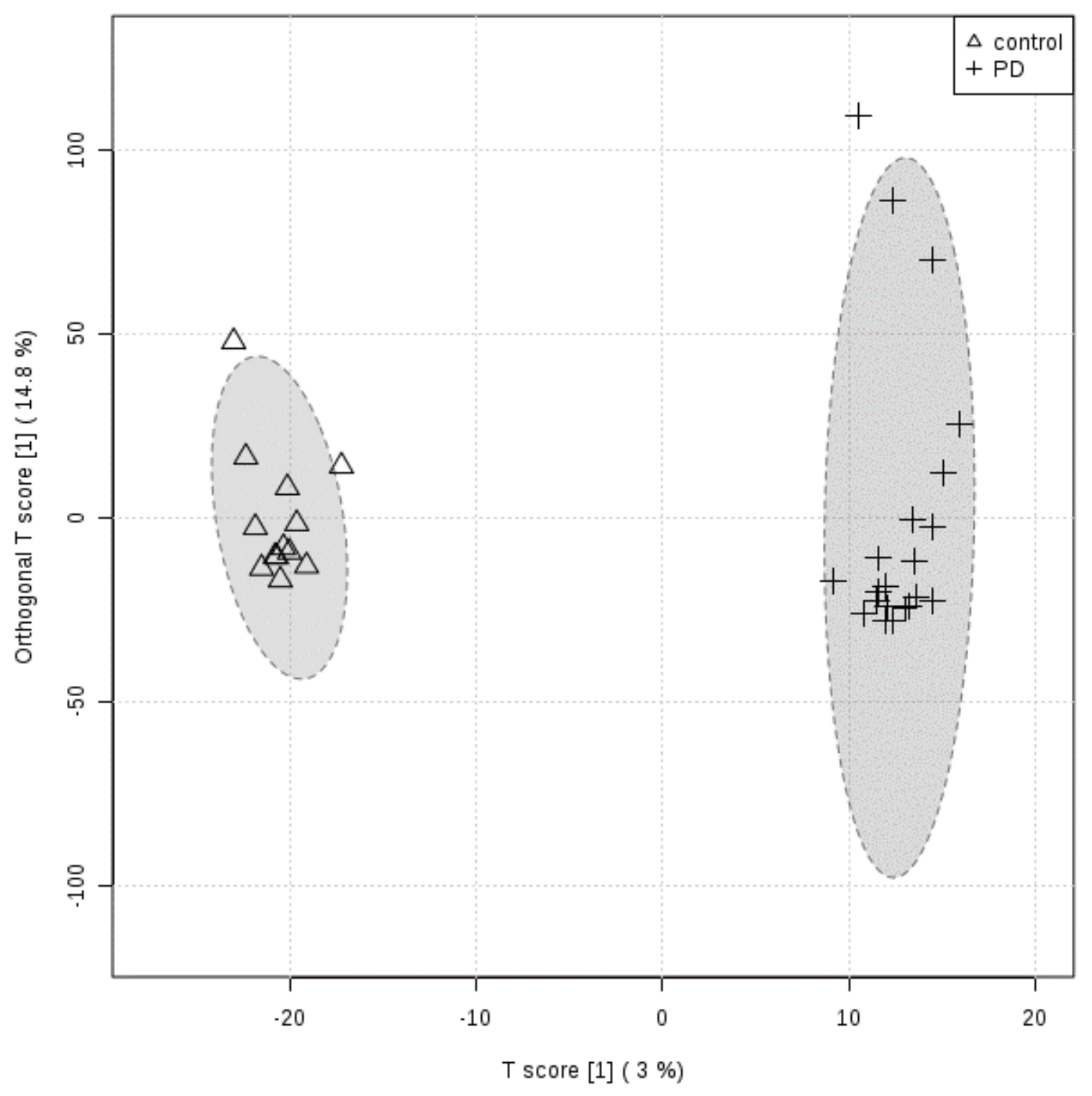

Supplementary Fig 1. OPLS-DA between PD and control metabolomes with PD drug metabolites manually removed. 
bioRxiv preprint doi: https://doi.org/10.1101/306266; this version posted May 22, 2018. The copyright holder for this preprint (which was not certified by peer review) is the author/funder, who has granted bioRxiv a license to display the preprint in perpetuity. It is made available under aCC-BY-NC-ND 4.0 International license.

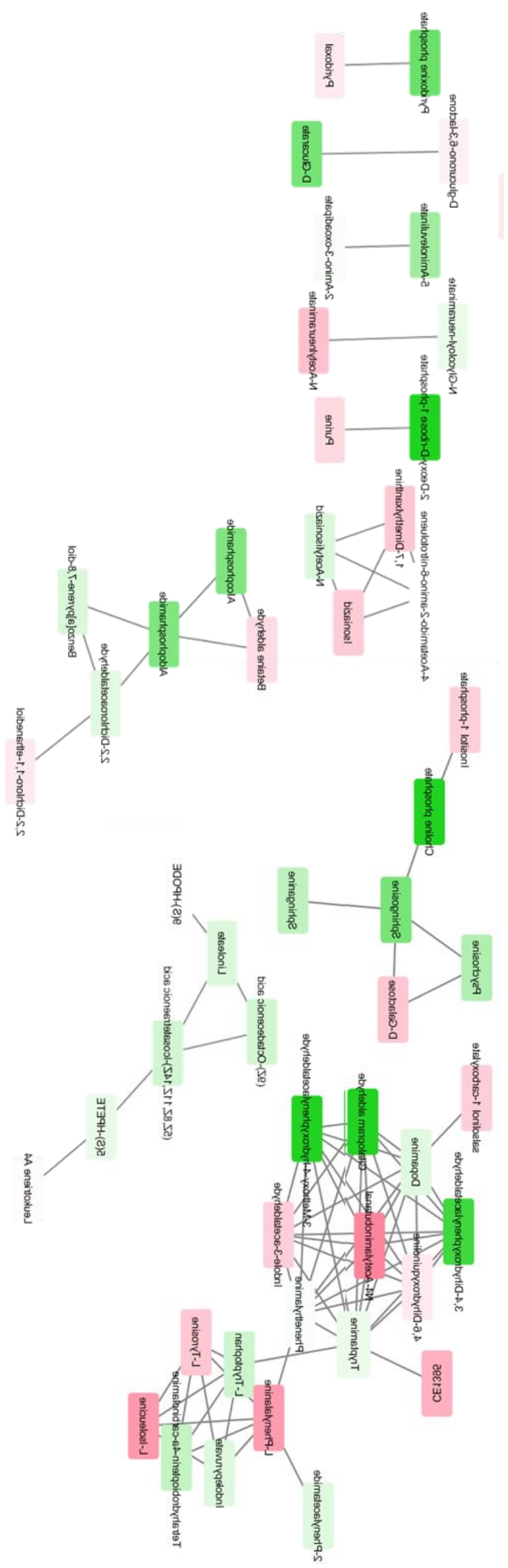

Supplementary Fig $\mathbf{2}$ (rotated $\mathbf{9 0}$ degrees for legibility) Network analysis of PD plasma analytes that correlate with I-dopa. Spearman correlation between each $m / z$ and L-dopa was calculated among PD patients. Darker shades of green correspond to stronger positive Spearman correlations; darker shades of red correspond to 
bioRxiv preprint doi: https://doi.org/10.1101/306266; this version posted May 22, 2018. The copyright holder for this preprint (which was not certified by peer review) is the author/funder, who has granted bioRxiv a license to display the preprint in perpetuity. It is made available under aCC-BY-NC-ND 4.0 International license.

stronger negative Spearman correlations.
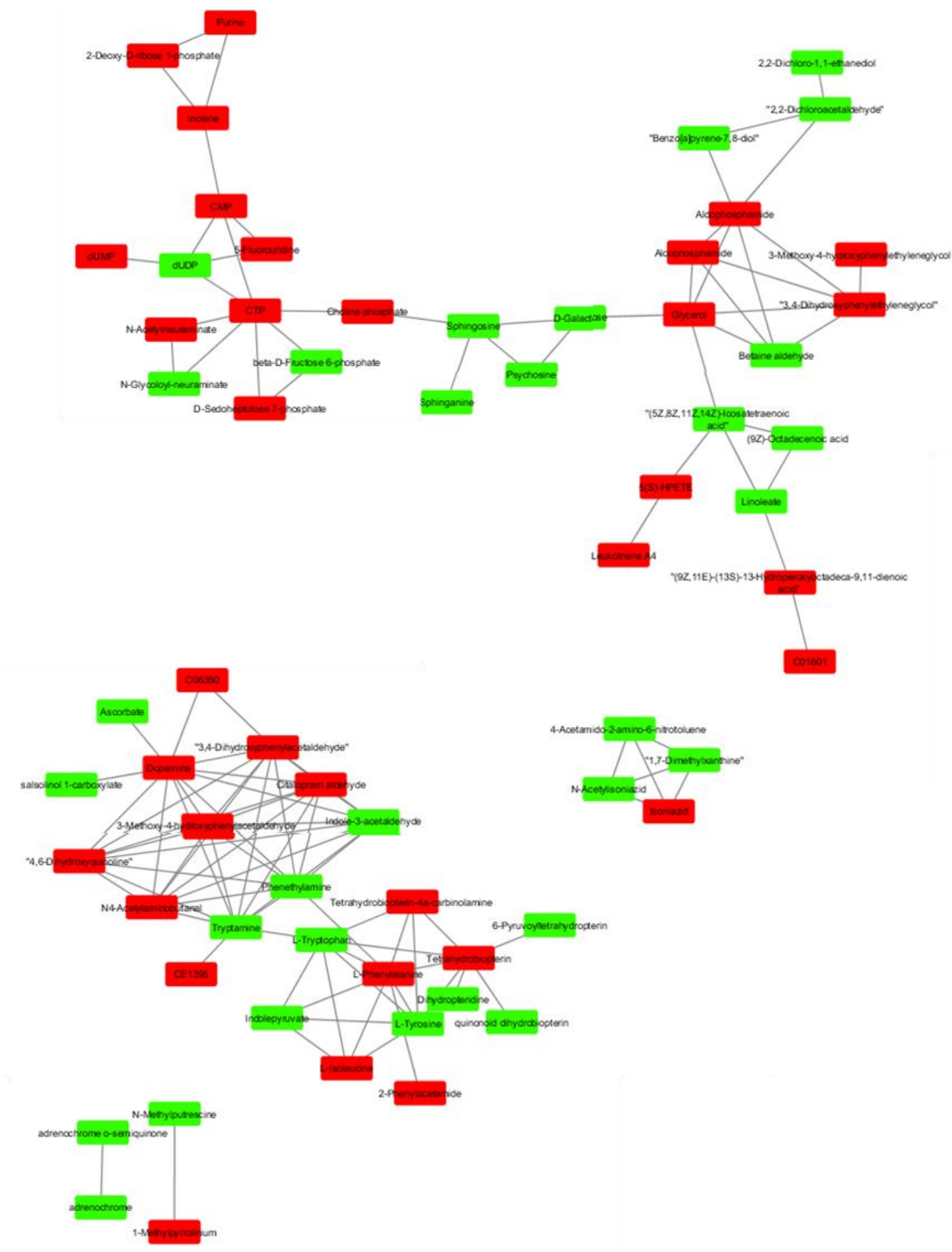

Supplementary Fig 3. Network analysis of the metabolites that are most different between PD and control patients. Red nodes correspond to metabolites elevated in PD patients compared to controls, while green nodes correspond to metabolites lower in PD patients compared to controls. 